\section{A Sociologia Moderna Teoria dos Sistemas}

Por Walter Buckley. São Paulo, Editora Cultrix, Editora da Universidade de São Paulo, 1971, 307 p.
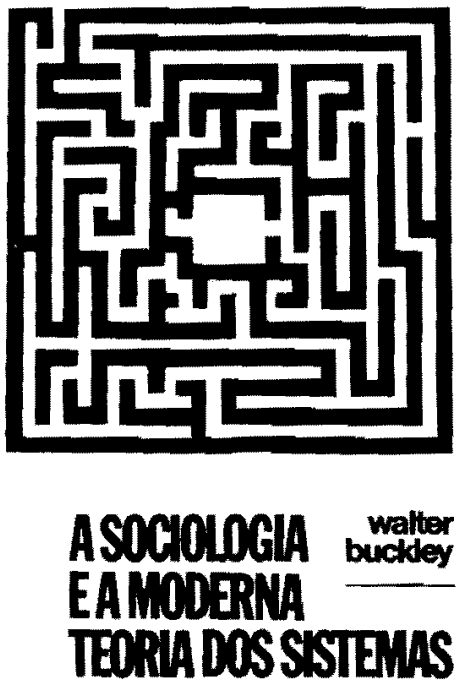

cultrix

O impacto da teoria geral de sistemas nas ciências, tanto naturais como sociais, ultrapassou em muito as ambições do biólogo Ludwig von Bertalanffy quando da publicaçõo, em 1950, do The theory of open systems in physics and biology, obra básica e fundamental para os teóricos sistêmicos, onde se concebeu o modelo do "sistema aberto" entendido como um "complexo de elementos em interação e em intercâmbio contínuo com o ambiente". A necessidade de se dar um tratamento metodológico semelhante às diversas áreas da ciência provocou, em algumas destas, histeria coletiva na aplicação da teoria geral de sistemas, especialmente de seu vocabulário característico. No entanto, ficou logo evidente a imaiuridade desta abordagem algo "revolucionária"; os que se tinham mantido céticos acabaram por devorar e, praticamente, destruir as potencialidades do modelo sistêmico, fazendo-lhe criticas praticamente irrefutáveis no então estágio de formulação.

A miscigenação da cibernética e da teoria da informação ou comunicação com a pesquisa geral dos sistemas veio dar uma nova vitalidade do modo de tratar o assunto, especialmente nas suas aplicaçōes no campo das ciências sociais. A introdução do conceito de elos de informação caracterizando as relações entre as "partes" ao invés de elos de energia, deram possibilidades aos investigadores de aplicarem o modelo de análise a fenômenos e situaçōes que não se prestavam ao estudo sob a égide da abordagem preliminar.

Walter Buckley penetra por baixo da superficialidade que caracteriza a maioria dos estudos que empregam os conceitos amplamente difundidos de input, output, feedback, etc., mas que não se preocupam em caracterizar mais especificamente os termos utilizados. Muito mais do que isso, Buckley faz um apelo aos cientistas sociais para aplicarem os instrumentos analíticos fornecidos pela teoria geral de sistemas, instrumentos estes bastante diversos daqueles que pertenciam à teoria quando da sua formulação inicial.

A sociologia, que sofreu $0 \mathrm{im}$ pacto da abordagem sistêmica quando da sua "opresentação" por von Bertalanffy, apresento hoje um quadro metodológico bastante complexo e confuso. $O$ funcionalismo parsoniano impregna a maioria dos trabalhos de cunho sociológico, dizendo abranger dentro da sua perspectiva a abordagem sistêmica. Assim, muitas das criticas dirigidas ao funcionalismo (críticas que podem ser classificadas em lógicas, substantivas e ideológicas) são utilizadas inadvertidamente para desmoralizar estudos sistêmicos jó realizados. A alegação de que o funcionalismo não pode explicar a mudança social, pois dá ênfase à persistência e à estabilidade, talvez não seja aplicável a uma teoria geral de morfogênese apresentada por Buckley. Trata-se, portanto, de distinguir entre a sistematicidade da perspectiva funcionalista e a teoria geral de sistemas propriamente dita.

$O$ apelo, portanto, feito por Walter Buckley, professor-adjunto de sociologia da Universidade da Califórnia, surge da crítica, apresentada aos modelos mecanicista e organicista (holística) que predominaram e predominam ainda na sociologia. O primeiro capítulo, modelos de sistemas so- ciais, é dedicado a um resumo critico destas duas metodologias básicas, seguido de uma comparação também crítica das estruturas teóricas de Homans e de Parsons.

O segundo capítulo é talvez o mais importante em termos de uma elaboração teórica de uma abordagem sociológica. O autor não se propõe a fazer uma extensa conceituação de "sistema" mas, apenas, elucidar as características inerentes aos sitemas adaptativos complexos que thes dão a capacidade de "elaborar ou mudar a estrutura como pré-requisito para permanecerem viáveis como sistema operantes". Nesse sentido, Buckley elabora um modelo abstrato de morfogênese, o qual utiliza conceitos como "meio", "variedade" e "coerção" para caracterizar os "processos que tendem a elaborar ou mudar a forma, a estrutura ou o estado de um sistema".

Em seguida, o Professor Buckley distingue "sistema" de "estrutura", procurando diferenciar os dois conceitos que não raro se confundem na abordagem funcionalista. "Sistema" é entendido como sendo uma "relação contínua, mantenedora de limites e variamente relacionada", enquanto a "estrutura pode assumir seus componentes em qualquer momento determinado". Assim, o quarto capítulo é dedicado ao exame da natureza particularmente fluida da estrutura dos sistemas socio culturais e à tênue linha divisória conceptual entre essa "estrutura" e o que se denomina "processo". Procura-se também discutir o "ato social" e o processo básico de interação examinando os modelos de Newcomb (modelo A-B-X), a teoria interpessoal da personalidade de Secord e Backman, e a teoria comportamental da comunicação de Ackoff.

Com este quadro conceptual de interação humana já definido, - quinto capítulo trata da contínua estruturação, desestruturação e reestruturaçãa característica do sistema socio cultural. Enquanto que no capítulo anterior a ênfase era sobre os microprocessos de relaçōes interpessoais, no capitulo subseqüiente o prisma principal é a organização social, seus papéis, e instituiçõos. Buckley insere o modelo abstrato do processo morfogênico, que constitui, segundo o autor, um "qua- 
dro de referência muito geral, dentro do qual se podem organizor inúmeras conceptualizações correntes da gênese, da manutenção ou da mudança da estrutura social", com o intuito de caracterizar o desenvolvimento das instituiçōes, ou então, das estruturas sócio-culturais. Durante toda a exposição teórica, o autor preocupa-se em demonstrar a "superio-

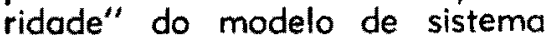
adaptativo complexo, em contraste com a fragilidade do modelo de sistema homeostático ou de equilíbrio, pois aquele vê o sistema socio cultural como um complexo sistema adaptativo que continuamente gera, elabora e reestrutura padrōes de significados, ações $e$ interações.

O modelo atual de "consenso" é brevemente exposto e criticado, pois Buckley alega que este mantém uma visão relativamente estática de "instituição" "controle social", e "ordem" e "desordem" social. Portanto, o sexto e último capítulo é dedicado ao exame de uma possível abordagem cibernética a estes mesmos conceitos, atribuindo-Ihes, assim, uma natureza mais dinâmica. A discussão engloba problemas referentes ao poder, à legitimidade, e à autoridade, como também trata de aspectos da inter-relação entre o poder e a burocracia.

A sociologia e a moderna teoria dos sistemas é muito mais do que uma mera aplicação da teoria geral dos sistemas a um campo específico do conhecimento. As críticas dirigidas às abordagens mecanicista e organicista (isto é, funcionalista), e a exposição clara e lógica do modelo sistêmico adaptativo ultrapassam, em muito, as fronteiras, ainda que fluidas, da ciência sociológica. $O$ apelo do Professor Buckley para que haja uma significativa revisão da teoria sociológica deve ser atendido pelos demais cientistas sociais.

sis:

Franklin Lee Feder

\section{Boss: Richard J. Daley of Chicago}

Por Mike Royko. Nova York, The New American Library, Inc., $1971,224 \mathrm{p}$.

Richard J. Daley é prefeito de Chicago há 15 anos. Mike Royko é um jornalista "radical". Daley atraiu o ódio dos jovens "radicais" norte-americanos quando, em 1968, durante a convenção do Partido Democrático, autorizou a policia a usar de violêncio para dispersar os jovens radicais que protestavam contra o envolvimento norte-americano no Vietnã. Mike Royko escreveu este livro para "denunciar as maneiras antidemocráticas" utilizadas por Daley para se manter na Prefeitura de Chicago e obter o apoio da elite partidária nacional. O livro, portanto, pretende ser uma crítica ao estilo político de Daley, e o leitor deve, ao terminá-lo estar detestando o prefeito de Chicago e a "máquina partidá-

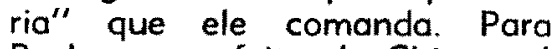
Royko, o prefeito de Chicago é um bandido; a democracia norteamericana, $O$ sheriff. $E$, como em todo o western produzido em $\mathrm{Hol}$ lywood, o mocinho, no fim, deve vencer $\circ$ bandido (ainda que o vitória demore mais de 15 anos).

Entretanto, nada disso acontece com o leitor. A gente termina o livro sem detestar Daley.
Acho até que desenvolvi um sentimento de respeito e admiração pelo prefeito de Chicago graças ao livro de Royko.

Por que, então, o livro de Royko não atinge seus objetivos? Creio que a resposta pode ser encontrada na maneira como Royko concebe a política. Para ele, a política é uma atividade executada por atores, sem qualquer conexão com a estrutura mais ampla em que tais atores estão inseridos e da qual fazem parte. Por isso, Daley é o bandido, o homem que comanda a "máquina" de Chicago, que possui, enfim, os destinos da cidade em sua mãos.

Em nenhum momento do livro Royko consegue superar essa visão idealista da política nem responder a pergunta que o leitor estó interessado em ver discutida e analisada, ou seja, quais as forças socioeconômicas e políticas que garantem o sucesso de Daley? Em outras palavras, por que Daley, com todos os defeitos que Royko aponta, conseguiu ser eleito prefeito de Chicago cinco vezes, com os votos da maioria esmagadora da população? Por que Daley, sendo o político corrupto que Royko retrata, possui um tremendo poder junto à cúpula do Partido Democrático? Por que Daley precisa ser consultado e cortejado pelos candidatos do Partido à presidência da República? No momento em que esta resenho está sendo escrita, George McGovern, candidato do Partido Democrático à presidência da República, corteja Daley e solicita o seu apoio e é lógico que não é simplesmente porque Daley controla a "máquina" de Chicago que McGovern precisa de seu apoio.

Royko não percebe que Daley é um político muito bem sucedido tanto no nível das massas de Chicago como no nível da política partidária norte-americana. Royko não percebe, enfim, que Daley é, ao mesmo tempo, um produto da democracia norte-americana e um "tipo" de político dessa mesma democracia.

E claro que não pretendo sugerir que a democracia norteamericana produz apenas políticos corruptos. O que pretendo sugerir é que a democracia norteamericana é capaz de produzir também políticos corruptos pois ela não depende da honestidade 